\title{
Como os brasileiros acessam a Atenção Básica em Saúde: evolução e adversidades no período recente (2012-2018)
}

\author{
How Brazilians access Primary Health Care: \\ evolution and adversities in recent times (2012-2018)
}

Allan Nuno Alves de Sousa (https://orcid.org/0000-0002-8689-1347) ${ }^{1}$

Helena Eri Shimizu (https://orcid.org/0000-0001-5612-5695) ${ }^{2}$

${ }^{1}$ Departamento de Saúde da Família, Secretaria de Atenção Primária à Saúde, Ministério da Saúde. Esplanada dos Ministérios Bloco G Edifício Sede 7० Andar. 70058-900 Brasília DF Brasil.

alnunos@gmail.com

${ }^{2}$ Departamento de Saúde

Coletiva, Faculdade

de Ciências da Saúde,

Universidade de Brasília.

Brasília DF Brasil.

\begin{abstract}
The scope of this study is to analyze access to primary care in Brazil between 2012 and 2018, taking into consideration the availability of services and the physical-structural, temporal and organizational characteristics of the primary care units and teams, highlighting the main advances and obstacles to their enhancement in different contexts. It involved a descriptive crosssectional and longitudinal study, with a quantitative approach based on secondary data from the National Program for the Improvement of Access and Quality of PC and population coverage data from the Ministry of Health. A total of 15,378 teams were selected and data screened from 59,354 users relating to the teams selected for 2012, and 56,369 users for 2018. Improvements were noted with respect to service availability and in terms of physical and architectural structure; the majority of the teams implemented and/or qualified the reception to spontaneous demand, including emergency care, improved the ways of organizing the agenda to foster a more integrated contact between users and health professionals and qualified the ways of scheduling and reduced the waiting times between scheduling and care. However, the persistence of recurring problems that need to be addressed to improve access to primary care in the country was detected.
\end{abstract}

Key words Primary care, Access to health services, Reception
Resumo O objetivo do estudo é analisar o acesso à atenção básica (AB) no Brasil, entre $2012 e$ 2018, considerando a disponibilidade de serviços, as características fisico-estruturais, temporais $e$ organizacionais das unidades básicas de saúde e das equipes, apontando seus principais avanços e obstáculos para a sua melhoria, em diferentes contextos. Estudo descritivo transversal e longitudinal, que utilizou a base de dados secundários do Programa Nacional de Melhoria do Acesso e da Qualidade da AB e dados de cobertura populacional do Ministério da Saúde. Foram selecionadas 15.378 equipes e mobilizados dados de 59.354 usuários referindo-se às equipes selecionadas para 2012 e 56.369 para 2018. Constataram-se melhorias quanto à disponibilidade de serviços $e$ nas condições de estrutura física e arquitetônica; a maioria das equipes implantaram elou qualificaram o acolhimento à demanda espontânea, incluindo atendimento a urgências, melhoraram os modos de organização da agenda para favorecer um contato mais fluído entre usuários e profissionais de saúde e qualificaram os modos de agendamento e diminuiram os tempos de espera entre o agendamento e o atendimento. Contudo, foram constatadas a persistência de problemas recorrentes que precisam ser enfrentados para a melhoria do acesso à atenção básica no país.

Palavras-chave Atenção básica, Acesso aos serviços de saúde, Acolhimento 


\section{Introdução}

O acesso à saúde representa categoria de fundamental relevância para a análise de todo sistema de saúde, dado que é capaz de revelar com maior nitidez elementos de natureza social e política presentes no processo de construção de políticas de saúde ${ }^{1}$. No cenário brasileiro recente, $o$ acesso à saúde figura como um dos mais importantes temas de debate, quando se toma em conta a efetivação do direito à saúde previsto na Constituição de 1988. Ao longo das últimas décadas, inúmeras iniciativas e esforços foram sendo gestados e implementados no âmbito do Sistema Único de Saúde (SUS) na perspectiva de assegurar a ampliação do acesso à população a serviços de saúde em todos os níveis de atenção ${ }^{2,3}$, contribuindo para a mitigação das profundas desigualdades que insistem em existir no país.

Nesse contexto, a atenção básica (AB) ganha destaque por sua capilaridade e capacidade de deslocar uma dada ênfase do cuidado em saúde, quase que exclusivamente centrada nos serviços, para uma perspectiva que pressupõe que as condições de saúde dos indivíduos estão fortemente relacionadas às dimensões sociais, políticas e econômicas em que estão inseridos ${ }^{4}$.

Um dos principais elementos que caracterizam a $A B$ é a sua proximidade territorial ao local de moradia das pessoas e sua maior possibilidade de funcionar como ponto de primeiro contato do sistema de saúde. A disponibilidade de serviços de $\mathrm{AB}$ no Brasil ganhou maior impulso a partir da criação do Programa Saúde da Família (PSF) em meados dos anos 1990 e, desde então, o país vivenciou um período de rápida expansão das coberturas populacionais, marcado por momentos de maior ou menor expansão a depender do momento político e econômico vivido pelo país, e por significativas diferenças regionais. A cobertura nacional da Saúde da Família (SF) saiu de 6,5\% em 1998 para 64,2\% em 2018, com um crescimento médio anual para o período igual a 2,9 pontos percentuais ${ }^{5}$.

Como resultado desse aumento das coberturas de $\mathrm{AB}$, variados estudos passaram a evidenciar os bons resultados produzidos pela SF, o que demonstrou a sua capacidade de produzir importantes efeitos nas condições de saúde da população, com melhoras no acesso e a utilização de serviços, impactando nos indicadores de mortalidade infantil e adulta, para algumas condições sensíveis à $\mathrm{AB}$, com ampliação do acesso a tratamentos e uma melhor equidade e a eficiência do SUS, considerando a sua contribuição para a redução de hospitalizações desnecessárias ${ }^{6}$.
Contudo, estudos evidenciam que, apesar de amplas coberturas e dos bons resultados produzidos pela $\mathrm{AB}$, ainda persistem importantes obstáculos para o acesso à rede básica de saúde no Brasil. Existem vazios assistenciais com necessidade de ampliação da oferta de serviço e cadastramento de usuários ${ }^{7}$; má distribuição das Unidades Básicas de Saúde (UBS) ao longo do território ${ }^{8}$; barreiras arquitetônicas na estrutura física das UBS que dificultam a utilização dos serviços, principalmente para pessoas com dificuldade de mobilidade'; inadequação do horário de funcionamento para atender às necessidades dos usuários ${ }^{8}$; inexistência ou baixa qualidade do acolhimento $^{10}$; restrições para o agendamento de atendimentos ${ }^{11}$; e longos tempos de espera entre $o$ agendamento e o atendimento ${ }^{8,10}$.

Como aponta a literatura que trata do tema, a conceituação do termo acesso possui um caráter polissêmico, encontrando diversificadas abordagens teórico-metodológicas que procuram delinear elementos concretos que permitem a aferição da abrangência e qualidade do acesso aos serviços de saúde ${ }^{12-14}$. De todo modo, existe certa convergência em direção a um conjunto de características gerais que demarcam a ideia de acesso, com destaque para a disponibilidade de serviços em relação à necessidade ${ }^{12,15}$; a localização geográfica adequada ${ }^{13,15,16}$; a oferta ajustada às condições socioeconômicas dos usuários ${ }^{12,13,15-17}$; a oferta que respeite normas, condutas, costumes e símbolos culturais da população ${ }^{15,16}$; o acolhimento como tecnologia de facilitação do modo como os serviços recebem e escutam os usuários $^{15}$; a adequação funcional na perspectiva organizativa, com o ajustamento da maneira como os serviços se organizam e se adaptam para assegurar e facilitar a entrada e o percurso dos usuários durante o seu contato com a unidade de saúde ${ }^{15}$; a continuidade do tratamento nas situações em que se exige ${ }^{17}$; e a aceitabilidade, que representa a relação entre as atitudes dos usuários frente ao que lhes é oferecido e a disposição dos trabalhadores em garantir um bom cuidado ${ }^{12,15}$.

Para Donabedian, o acesso pode ser diferenciado em duas grandes dimensões, geográfica e sócio-organizacional, enquanto a primeira engloba os fatores que podem aumentar a dificuldade de alcançar o serviço de saúde, tais como distância, tempo e custo para o deslocamento, a segunda se refere a todas as demais características que envolve o acesso, tais como a maneira de ingressar e receber o cuidado na unidade de saúde ${ }^{16}$. Ao mesmo tempo, alguns autores destacam como o conceito de acesso foi se deslocando de uma dada concepção que o entendia apenas como elemen- 
to de ingresso nos serviços para uma concepção que considera as inter-relações entre o contato e a qualidade dos cuidados recebidos ${ }^{14}$.

Como aponta Travassos ${ }^{14}$, o conceito de acesso, em muitas situações, é utilizado de maneira imprecisa e, por vezes, há variação até mesmo na terminologia adotada, sendo que alguns autores preferem utilizar o substantivo acessibilidade para se referirem àquilo que é acessível. De toda maneira, empregaremos o termo acesso como equivalente a acessibilidade para a análise desenvolvida no presente estudo. Aqui entendese acesso a $A B$ como a existência do serviço em quantidade suficiente, localizado em espaço geográfico que favoreça o deslocamento e o ingresso dos usuários no serviço, com acolhimento e oferta adequada às suas necessidades, em tempo oportuno, respeitando aspectos de natureza socioculturais.

O objetivo do presente estudo é analisar o acesso dos usuários à $\mathrm{AB}$ no Brasil, entre os anos de 2012 e 2018, considerando a disponibilidade de serviços, características físico-estruturais, temporais e organizacionais das UBS e equipes, apontando seus principais avanços e mais importantes obstáculos para a sua melhoria, em diferentes contextos.

\section{Método}

Estudo descritivo transversal e longitudinal, que utilizou base de dados secundários do Programa Nacional de Melhoria do Acesso e Qualidade da Atenção Básica (PMAQ-AB), do primeiro (2012) e terceiro (2018) ciclos e dados sobre as coberturas populacionais de $\mathrm{AB}$, disponíveis no site do Ministério da Saúde (MS), para a análise da disponibilidade de serviços de $\mathrm{AB}^{5}$.

A coleta de dados do primeiro ciclo do PMAQ ocorreu entre maio e dezembro de 2012 e atingiu 17.482 equipes, correspondendo a cerca de $52 \%$ das equipes existentes no período da coleta. Ao mesmo tempo, foram entrevistados 65.391 usuários (média de 3,7 / equipe) que aguardavam atendimento na UBS no momento da coleta, selecionados ao acaso. A coleta do terceiro ciclo ocorreu entre julho de 2017 e agosto de 2018 , atingindo 38.865 equipes, o que corresponde a aproximadamente $94 \%$ das equipes que existiam no período da coleta de dados e, para esse ciclo, foram entrevistados 140.444 usuários (média de 3,6/equipe). A coleta foi realizada por 41 instituições de ensino e pesquisa, lideradas pela Universidade Federal de Pelotas (UFPel),
Universidade Federal de Minas Gerais (UFMG), Fundação Oswaldo Cruz (Fiocruz), Universidade Federal da Bahia (UFBA), Universidade Federal de Sergipe (UFS), Universidade Federal do Piauí (UFPI), Universidade Federal do Rio Grande do Norte (UFRN), Universidade Federal do Mato Grosso do Sul (UFMS) e Universidade Federal do Pará (UFPA).

Realizou-se estudo longitudinal, a partir da seleção de uma amostra que compreende o subconjunto de equipes que participaram tanto do primeiro, quanto do terceiro ciclo do programa, de modo a permitir análise que detecte mudanças no comportamento das dimensões relacionadas ao acesso para os mesmos casos com o passar do tempo, ou seja, buscou-se analisar se para cada variável selecionada constatou-se melhora, piora ou manutenção do cenário observado para as equipes participantes dos dois processos avaliativos.

Foram selecionadas 15.378 equipes que participaram do primeiro e do terceiro ciclos do PMAQ, de modo a permitir análise longitudinal dos mesmos casos. Os resultados concernentes às UBS foram replicados para todas as equipes que atuavam na mesma UBS, e foram selecionados 59.354 usuários que responderam aos instrumentos referindo-se às equipes selecionadas no primeiro ciclo e 56.369 usuários no terceiro ciclo.

Para testar se havia viés na distribuição das equipes que compõem a amostra, realizamos um teste de correlação entre a distribuição, por Unidade da Federação, de equipes selecionadas e o total de equipes avaliadas. O coeficiente $r$ de pearson encontrado foi igual a 0,999 para o primeiro ciclo e igual a 0,960 para o terceiro ciclo, demonstrando aleatoriedade na composição da amostra em relação a totalidade de equipes participantes do PMAQ.

Foram selecionadas variáveis que pudessem informar a situação do acesso à $\mathrm{AB}$ conforme as quatro dimensões analisadas: disponibilidade, fisico-estrutural, temporal e organizacional, organizadas em seis subdimensões conforme apresentado no diagrama (Figura 1).

Para cada subdimensão foram selecionadas variáveis que guardassem correspondência e compatibilidade de conteúdo, dado que os instrumentos de coleta de dados utilizados nos dois ciclos estudados não eram exatamente idênticos. Parte das questões se mantiveram inalteradas, parte passou por ajustes no enunciado das questões ou nas alternativas disponíveis, novas questões foram inseridas e outras foram suprimidas dos instrumentos. Desse modo, para garantir a 


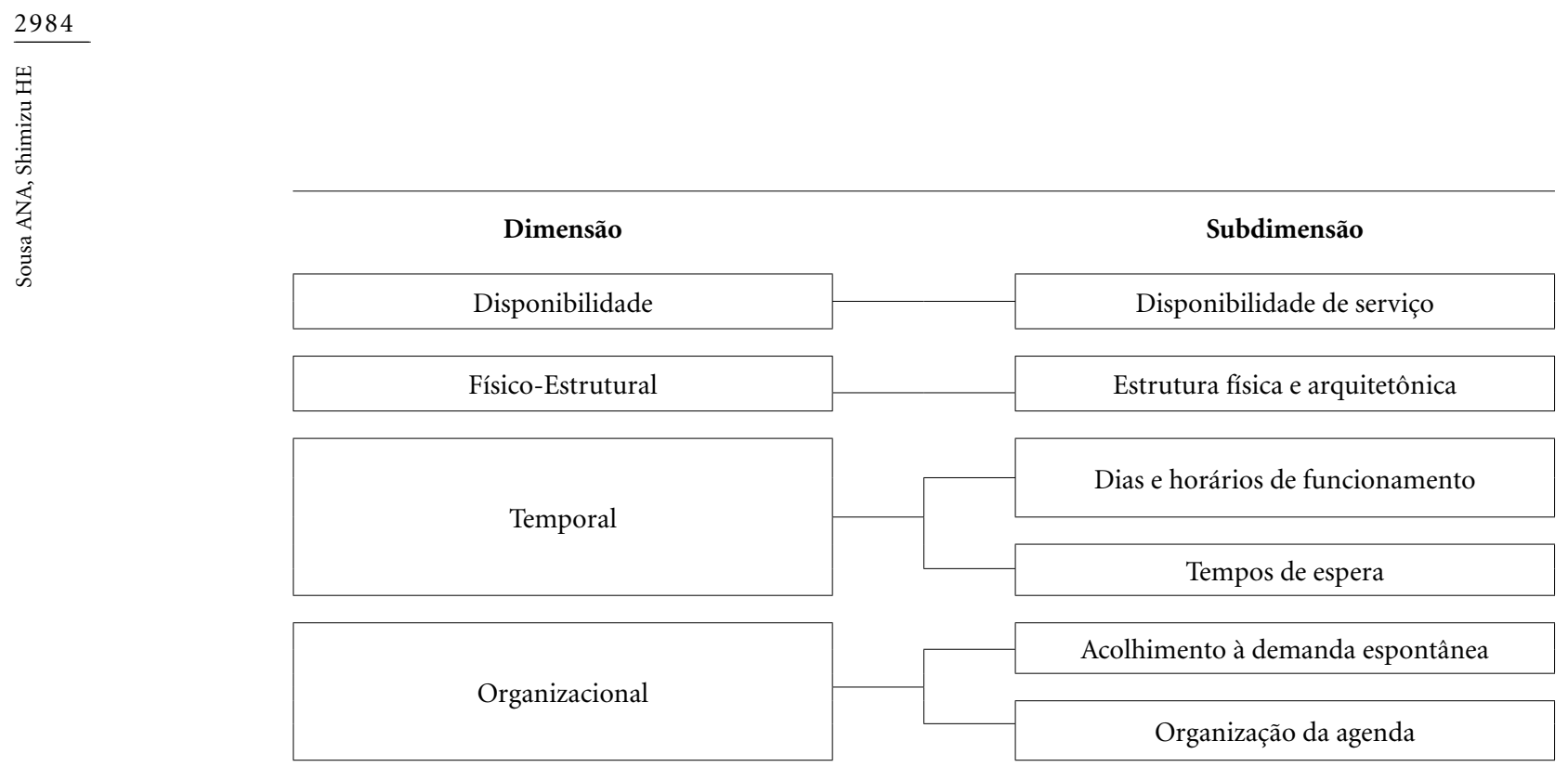

Figura 1. Dimensões e subdimensões de análise.

Fonte: Elaborado pelos autores.

comparabilidade das variáveis entre os dois períodos analisados, somente foram mobilizadas questões que mantiveram a congruência em seu objeto e sentido. Ao todo foram escolhidas 17 variáveis que se referem a dados das UBS e organização das equipes, tais como se a unidade é adaptada para permitir a entrada de cadeirantes, quais os dias da semana e horários de funcionamento, se a equipe possui acolhimento à demanda espontânea, se facilita o contato dos usuários para tirarem dúvidas pós consulta e qual o tempo de espera entre o agendamento da consulta e o atendimento; e 11 variáveis que se referem a percepção dos usuários, tais como se o horário de funcionamento da UBS atende às suas necessidades, se ele consegue ser escutado mesmo sem ter consulta agendada e se a consulta é realizada com horário marcado.

Para todas as variáveis eleitas, além da comparação dos seus resultados entre 2012 e 2018, os dados foram estratificados por região e porte populacional dos municípios nos quais atuavam as equipes e viviam os usuários que acessavam os serviços. Para o porte populacional, os municípios foram categorizados segundo a estimativa populacional do Instituto Brasileiro de Geografia e Estatística (IBGE) para 2012 (até 10.000 habitantes, de 10.001 a 20.000, 20.001 a 50.000, 50.001 a 100.000 e acima de 100.000 habitantes).

Os dados foram organizados e tratados em planilha eletrônica Microsoft Office Excel Professional Plus $2013^{\circledR}$. Para a análise dos dados refe- rentes ao acesso em cruzamento com a região e o porte populacional, aplicou-se o Teste de QuiQuadrado para proporções esperadas iguais em amostras de variáveis nominais e todos os valores de p-valor abaixo de 0,05 foram considerados estatisticamente significativos.

\section{Resultados}

Para a subdimensão disponibilidade de serviço, entre os anos de 2012 e 2018 as coberturas populacionais de $\mathrm{AB}$ no Brasil aumentaram de 68,3\% para 74,6\%. Quando se considera apenas as coberturas pela Estratégia Saúde da Família (ESF), a variação foi de quase 10 pontos percentuais, partindo de 55,5\% (33.899 equipes) e alcançando $64,2 \%$ (43.016 equipes).

Contudo, os dados nacionais agregados encobertam importantes diferenças regionais. Em 2018, enquanto o Sudeste possuía 68,6\% de cobertura de $\mathrm{AB}$ e apenas 53,0\% de cobertura pela ESF, o Nordeste possuía, respectivamente, 83,4\% e $79,7 \%$. O maior incremento na cobertura de AB geral, para o período analisado, foi no Norte $(63,1 \%-71,4 \%)$ e para a ESF no Sul $(54,9 \%$ $66,3 \%)$.

Quanto a estrutura física e arquitetônica, os dados revelam que houve importante melhoria nas condições estruturais das UBS para facilitar o acesso a pessoas com dificuldades de mobilidade. Aquelas unidades que possuíam porta e corredor 
de entrada adaptados para pessoas que utilizam cadeiras de rodas aumentou de $48,4 \%$ para $80,9 \%$, com corredores adaptados para cadeirantes, de $35,0 \%$ para $68,5 \%$, e portas internas adaptadas para cadeiras de rodas, de $34,8 \%$ para $67,3 \%$ (Tabela 1). As regiões Norte e Nordeste apresentaram os melhores avanços com elevações de mais de 40 pontos percentuais para todos os elementos observados. Quanto ao porte dos municípios, foram nas menores localidades que ocorreram as melhorias mais acentuadas (Tabela 1).

Para a subdimensão acolhimento à demanda espontânea, também pode-se observar melhoria na situação das equipes. A proporção delas que possuíam acolhimento implantando, saiu de $79,9 \%$ e alcançou 96,4\%, com maior destaque para o norte e centro-oeste. Do mesmo modo, são nas menores municipalidades que se verificou as melhorias mais expressivas na oferta de acolhimento nas unidades (Tabela 1). A melhoria do acolhimento nas UBS também se deu com a ampliação de dias e turnos em que ele ocorre. Em 2012, 70,3\% das equipes realizavam acolhimento ao menos cinco dias da semana e $68,7 \%$ em ao menos dois turnos, ao passo que em 2018 esses números alcançaram $90,1 \%$ e $93,7 \%$, respectivamente (Tabela 1).

Outro importante aspecto que envolve o acolhimento nas UBS é se há protocolos que orientem a prática dos profissionais para realizá-lo da maneira mais adequada e, nesse quesito, os dados do PMAQ também mostram evolução significativa. Enquanto em 2012, 38\% das equipes possuíam protocolo, em 2018 o percentual saltou

Tabela 1. Estrutura física e arquitetônica e acolhimento à demanda espontânea, segundo profissionais de saúde, por grande região e porte populacional, Brasil, 2012 e 2018.

\begin{tabular}{|c|c|c|c|c|c|c|c|c|}
\hline \multirow{3}{*}{$\begin{array}{c}\text { Subdimensão } \\
\text { Variáveis }\end{array}$} & \multicolumn{6}{|c|}{ Estrutura física e arquitetônica } & \multirow{2}{*}{\multicolumn{2}{|c|}{$\begin{array}{l}\begin{array}{c}\text { Acolhimento à demanda } \\
\text { espontânea }\end{array} \\
\begin{array}{l}\text { Acolhimento à demanda } \\
\text { espontânea implantado* }\end{array}\end{array}$}} \\
\hline & \multicolumn{2}{|c|}{$\begin{array}{c}\text { Porta de entrada adaptada } \\
\text { para cadeira de rodas }\end{array}$} & \multicolumn{2}{|c|}{$\begin{array}{l}\text { Corredores adaptados } \\
\text { para cadeira de rodas }\end{array}$} & \multicolumn{2}{|c|}{$\begin{array}{l}\text { Portas internas adaptadas } \\
\text { para cadeira de rodas }\end{array}$} & & \\
\hline & 2012 & $\begin{array}{l}2018 \\
(\mathrm{IC} 95 \%)\end{array}$ & $\begin{array}{l}2012 \\
(\mathrm{IC} 95 \%)\end{array}$ & $\begin{array}{c}2018 \\
\%(\text { IC } 95 \%)\end{array}$ & $\begin{array}{l}2012 \\
(\mathrm{IC} 95 \%)\end{array}$ & $\begin{array}{c}2018 \\
\%(\mathrm{IC} 95 \%)\end{array}$ & $\begin{array}{c}2012 \\
\%(\mathrm{IC} 95 \%)\end{array}$ & $\begin{array}{c}2018 \\
\%(\text { IC95\%) }\end{array}$ \\
\hline \multicolumn{9}{|l|}{ Região } \\
\hline & $8,1)$ & $\begin{array}{c}76,1 \\
(73,3-78,9)\end{array}$ & $\begin{array}{c}15,5 \\
(13,1-17,9)\end{array}$ & $\begin{array}{c}58,5 \\
(55,3-61,7)\end{array}$ & $\begin{array}{c}19,3 \\
(16,7-21,9)\end{array}$ & $\begin{array}{c}58,6 \\
(55,4-61,8)\end{array}$ & $\begin{array}{c}62,1 \\
(58,9-65,3)\end{array}$ & $\begin{array}{c}93,4 \\
(91,8-95,0)\end{array}$ \\
\hline Nord & $\begin{array}{c}35,5 \\
(34,2-36,8)\end{array}$ & $\begin{array}{c}78,9 \\
(77,8-80,0)\end{array}$ & $\begin{array}{c}21,3 \\
(20,2-22,4)\end{array}$ & $\begin{array}{c}61,5 \\
(60,2-62,8)\end{array}$ & $\begin{array}{c}21,4 \\
(20,3-22,5)\end{array}$ & $\begin{array}{c}61,5 \\
(60,2-62,8)\end{array}$ & $\begin{array}{c}70,3 \\
(69,0-71,6)\end{array}$ & $\begin{array}{c}96,0 \\
(95,5-96,5)\end{array}$ \\
\hline Sude & $\begin{array}{c}56,4 \\
(55,1-57,7)\end{array}$ & $\begin{array}{c}81,6 \\
(80,6-82,6)\end{array}$ & $\begin{array}{c}45,4 \\
(44,1-46,7)\end{array}$ & $\begin{array}{c}69,9 \\
(68,7-71,1)\end{array}$ & $\begin{array}{c}45,1 \\
(43,8-46,4)\end{array}$ & $\begin{array}{c}68,1 \\
(66,9-69,3)\end{array}$ & $\begin{array}{c}92,3 \\
(91,6-93,0)\end{array}$ & $\begin{array}{r}95 \\
(95,4-\end{array}$ \\
\hline$S$ & $\begin{array}{c}61,7 \\
(59,8-63,6)\end{array}$ & $\begin{array}{c}84,9 \\
(83,5-86,3)\end{array}$ & $\begin{array}{c}45,6 \\
(43,7-47,5)\end{array}$ & $\begin{array}{c}80,0 \\
(78,5-81,5)\end{array}$ & $\begin{array}{c}43,7 \\
(41,8-45,6)\end{array}$ & $\begin{array}{c}78,7 \\
(77,1-80,3)\end{array}$ & $\begin{array}{c}81,8 \\
(80,3-83,3)\end{array}$ & $\begin{array}{c}97,7 \\
(97,1-98,3)\end{array}$ \\
\hline & $\begin{array}{c}42,0 \\
(39,0-45,0)\end{array}$ & 81,6 & 32,1 & $\begin{array}{c}74,3 \\
(71,7-76,9)\end{array}$ & $\begin{array}{c}31,9 \\
(29,1-34,7)\end{array}$ & $\begin{array}{c}70,2 \\
(67,4-73,0)\end{array}$ & $\begin{array}{c}67,0 \\
(64,2-69,8)\end{array}$ & $\begin{array}{c}99,4 \\
(98,9-99,9)\end{array}$ \\
\hline \multicolumn{9}{|c|}{ Porte Populacional } \\
\hline $00^{(\mathrm{f})}$ & $\begin{array}{c}55,3 \\
(53,2-57,4)\end{array}$ & $\begin{array}{c}86,7 \\
(85,3-88,1)\end{array}$ & $\begin{array}{c}41,2 \\
(39,2-43,2)\end{array}$ & $\begin{array}{c}77,1 \\
(75,4-78,8)\end{array}$ & $\begin{array}{c}40,0 \\
(38,0-42,0)\end{array}$ & $\begin{array}{c}75,5 \\
(73,7-77,3)\end{array}$ & $\begin{array}{c}67,9 \\
(66,0-69,8)\end{array}$ & $\begin{array}{r}98 \\
(98,2\end{array}$ \\
\hline $\begin{array}{l}10.001 \mathrm{a} \\
20.000^{(\mathrm{g})}\end{array}$ & $\begin{array}{c}41,2 \\
(39,3-43,1)\end{array}$ & $\begin{array}{c}80,5 \\
(78,9-82,1)\end{array}$ & $\begin{array}{c}28,1 \\
(26,3-29,9)\end{array}$ & $\begin{array}{c}69,0 \\
(67,2-70,8)\end{array}$ & $\begin{array}{c}28,2 \\
(26,4-30,0)\end{array}$ & $\begin{array}{c}68,9 \\
(67,1-70,7)\end{array}$ & $\begin{array}{c}73,5 \\
(71,8-75,2)\end{array}$ & $\begin{array}{c}98,3 \\
(97,8-98,8)\end{array}$ \\
\hline $\begin{array}{l}20.001 \mathrm{a} \\
50.000^{(\mathrm{h})}\end{array}$ & $\begin{array}{c}42,2 \\
(40,5-43,9)\end{array}$ & $\begin{array}{c}80,7 \\
(79,4-82,0)\end{array}$ & $\begin{array}{c}27,1 \\
(25,6-28,6)\end{array}$ & $\begin{array}{c}66,2 \\
(64,6-67,8)\end{array}$ & $\begin{array}{c}28,3 \\
(26,8-29,8)\end{array}$ & $\begin{array}{c}65,1 \\
(63,5-66,7)\end{array}$ & $\begin{array}{c}79,5 \\
(78,1-80,9)\end{array}$ & $\begin{array}{c}99,1 \\
(98,8-99,4)\end{array}$ \\
\hline $\begin{array}{l}50.001 \mathrm{a} \\
100.000^{(\mathrm{i})}\end{array}$ & $\begin{array}{c}41,7 \\
(39,3-44,1)\end{array}$ & $\begin{array}{c}78,7 \\
(76,7-80,7)\end{array}$ & $\begin{array}{c}27,9 \\
(25,7-30,1)\end{array}$ & $\begin{array}{c}65,6 \\
(63,3-67,9)\end{array}$ & $\begin{array}{c}28,0 \\
(25,8-30,2)\end{array}$ & $\begin{array}{c}63,1 \\
(60,8-65,4)\end{array}$ & $\begin{array}{c}78,8 \\
(76,8-80,8)\end{array}$ & $\begin{array}{c}98,0 \\
(97,3-98,7)\end{array}$ \\
\hline $\begin{array}{l}100.000 \text { ou } \\
\text { mais }^{(j)}\end{array}$ & $\begin{array}{c}54,6 \\
(53,3-55,9)\end{array}$ & $\begin{array}{c}79,9 \\
(78,8-81,0)\end{array}$ & $\begin{array}{c}42,7 \\
(41,4-44,0)\end{array}$ & $\begin{array}{c}67,1 \\
(65,9-68,3)\end{array}$ & $\begin{array}{c}41,7 \\
(40,4-43,0)\end{array}$ & $\begin{array}{c}66,1 \\
(64,9-67,3)\end{array}$ & $\begin{array}{c}88,4 \\
(87,6-89,2)\end{array}$ & $\begin{array}{c}92,8 \\
(92,1-93,5)\end{array}$ \\
\hline Brasil $^{(\mathrm{k})}$ & $\begin{array}{c}48,4 \\
(47,6-49,2)\end{array}$ & $\begin{array}{c}80,9 \\
(80,3-81,5)\end{array}$ & $\begin{array}{c}35,0 \\
(34,2-35,8)\end{array}$ & $\begin{array}{c}68,5 \\
(67,8-69,2)\end{array}$ & $\begin{array}{c}34,8 \\
(34,0-35,6)\end{array}$ & $\begin{array}{c}67,3 \\
(66,6-68,0)\end{array}$ & $\begin{array}{c}79,9 \\
(79,3-80,5)\end{array}$ & $\begin{array}{c}96,4 \\
(96,1-96,7)\end{array}$ \\
\hline
\end{tabular}




\begin{tabular}{|c|c|c|c|c|c|c|c|c|c|}
\hline \multirow[t]{17}{*}{ 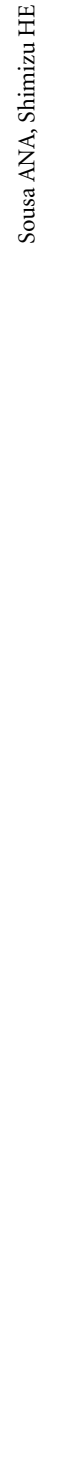 } & orte po & $\begin{array}{l}\text { física e al } \\
\text { l, Brasil, }\end{array}$ & $\begin{array}{l}\text { tônica e a } \\
\text { e } 2018 \text {. }\end{array}$ & & & & & & \\
\hline & Subdimensão & & & Acolh & imento à den & landa espontâ & inea & & \\
\hline & \multirow[t]{2}{*}{ Variáveis } & \multicolumn{2}{|c|}{$\begin{array}{c}\text { Realiza acolhimento à } \\
\text { demanda espontânea ao } \\
\text { menos } 5 \text { dias por semana }\end{array}$} & \multicolumn{2}{|c|}{$\begin{array}{l}\text { Realiza acolhimento à } \\
\text { demanda espontânea ao } \\
\text { menos } 2 \text { turnos por } \text { dia }^{*}\end{array}$} & \multicolumn{2}{|c|}{$\begin{array}{l}\text { Possui protocolo para } \\
\text { acolhimento à demanda } \\
\text { espontânea/urgência }{ }^{\star}\end{array}$} & \multicolumn{2}{|c|}{$\begin{array}{l}\text { Realiza atendimento de } \\
\text { urgência e emergência }\end{array}$} \\
\hline & & $\begin{array}{c}2012 \\
\%(\mathrm{IC} 95 \%)\end{array}$ & $\begin{array}{c}2018 \\
\%(\text { IC95\%) }\end{array}$ & $\begin{array}{c}2012 \\
\%(\text { IC95\%) }\end{array}$ & $\begin{array}{c}2018 \\
\%(\text { IC95\%) }\end{array}$ & $\begin{array}{c}2012 \\
\%(\text { IC95\%) }\end{array}$ & $\begin{array}{c}2018 \\
\%(\text { IC } 95 \%)\end{array}$ & $\begin{array}{c}2012 \\
\%(\text { IC } 95 \%)\end{array}$ & $\begin{array}{c}2018 \\
\%(\text { IC } 95 \%)\end{array}$ \\
\hline & \multicolumn{9}{|l|}{ Região } \\
\hline & Norte $^{(a)}$ & $\begin{array}{c}51,7 \\
(48,4-55,0)\end{array}$ & $\begin{array}{c}84,3 \\
(81,9-86,7)\end{array}$ & $\begin{array}{c}52,7 \\
(49,5-55,9)\end{array}$ & $\begin{array}{c}92,3 \\
(90,6-94,0)\end{array}$ & $\begin{array}{c}21,2 \\
(18,5-23,9)\end{array}$ & $\begin{array}{c}55,7 \\
(52,5-58,9)\end{array}$ & $\begin{array}{c}60,6 \\
(57,4-63,8)\end{array}$ & $\begin{array}{c}83,0 \\
(80,6-85,4)\end{array}$ \\
\hline & Nordeste $^{(b)}$ & $\begin{array}{c}53,9 \\
(52,5-55,3)\end{array}$ & $\begin{array}{c}87,0 \\
(86,1-87,9)\end{array}$ & $\begin{array}{c}53,3 \\
(51,9-54,7)\end{array}$ & $\begin{array}{c}89,4 \\
(88,6-90,2)\end{array}$ & $\begin{array}{c}26,6 \\
(25,4-27,8)\end{array}$ & $\begin{array}{c}80,4 \\
(79,3-81,5)\end{array}$ & $\begin{array}{c}68,6 \\
(67,3-69,9)\end{array}$ & $\begin{array}{c}94,2 \\
(93,6-94,8)\end{array}$ \\
\hline & Sudeste ${ }^{(c)}$ & $\begin{array}{c}84,6 \\
(83,7-85,5)\end{array}$ & $\begin{array}{c}90,7 \\
(89,9-91,5)\end{array}$ & $\begin{array}{c}82,0 \\
(81,0-83,0)\end{array}$ & $\begin{array}{c}95,5 \\
(95,0-96,0)\end{array}$ & $\begin{array}{c}53,7 \\
(52,4-55,0)\end{array}$ & $\begin{array}{c}83,6 \\
(82,6-84,6)\end{array}$ & $\begin{array}{c}75,8 \\
(74,7-76,9)\end{array}$ & $\begin{array}{c}92,0 \\
(91,3-92,7)\end{array}$ \\
\hline & $\mathrm{Sul}^{(\mathrm{d})}$ & $\begin{array}{c}78,7 \\
(77,1-80,3)\end{array}$ & $\begin{array}{c}95,4 \\
(94,6-96,2)\end{array}$ & $\begin{array}{c}77,0 \\
(75,4-78,6)\end{array}$ & $\begin{array}{c}97,5 \\
(96,9-98,1)\end{array}$ & $\begin{array}{c}36,8 \\
(34,9-38,7)\end{array}$ & $\begin{array}{c}83,1 \\
(81,7-84,5)\end{array}$ & $\begin{array}{c}82,0 \\
(80,5-83,5)\end{array}$ & $\begin{array}{c}95,5 \\
(94,7-96,3)\end{array}$ \\
\hline & $\begin{array}{l}\text { Centro- } \\
\text { Oeste }^{(\mathrm{e})}\end{array}$ & $\begin{array}{c}63,2 \\
(60,3-66,1)\end{array}$ & $\begin{array}{c}94,2 \\
(92,8-95,6)\end{array}$ & $\begin{array}{c}61,0 \\
(58,1-63,9)\end{array}$ & $\begin{array}{c}95,8 \\
(94,6-97,0)\end{array}$ & $\begin{array}{c}21,6 \\
(19,1-24,1)\end{array}$ & $\begin{array}{c}75,9 \\
(73,3-78,5)\end{array}$ & $\begin{array}{c}66,4 \\
(63,5-69,3)\end{array}$ & $\begin{array}{c}95,3 \\
(94,0-96,6)\end{array}$ \\
\hline & \multicolumn{9}{|c|}{ Porte Populacional } \\
\hline & Até $10.000^{(\mathrm{f})}$ & $\begin{array}{c}58,1 \\
(56,1-60,1)\end{array}$ & $\begin{array}{c}92,0 \\
(90,9-93,1)\end{array}$ & $\begin{array}{c}60,1 \\
(58,1-62,1)\end{array}$ & $\begin{array}{c}95,7 \\
(94,9-96,5)\end{array}$ & $\begin{array}{c}24,0 \\
(22,2-25,8)\end{array}$ & $\begin{array}{c}80,4 \\
(78,8-82,0)\end{array}$ & $\begin{array}{c}73,6 \\
(71,8-75,4)\end{array}$ & $\begin{array}{c}95,1 \\
(94,2-96,0)\end{array}$ \\
\hline & $\begin{array}{l}10.001 \mathrm{a} \\
20.000^{(\mathrm{g})}\end{array}$ & $\begin{array}{c}61,1 \\
(59,2-63,0)\end{array}$ & $\begin{array}{c}90,0 \\
(88,8-91,2)\end{array}$ & $\begin{array}{c}62,5 \\
(60,6-64,4)\end{array}$ & $\begin{array}{c}93,4 \\
(92,4-94,4)\end{array}$ & $\begin{array}{c}25,3 \\
(23,6-27,0)\end{array}$ & $\begin{array}{c}79,9 \\
(78,3-81,5)\end{array}$ & $\begin{array}{c}63,9 \\
(62,0-65,8)\end{array}$ & $\begin{array}{c}94,7 \\
(93,8-95,6)\end{array}$ \\
\hline & $\begin{array}{l}20.001 \mathrm{a} \\
50.000^{(\mathrm{h})}\end{array}$ & $\begin{array}{c}68,1 \\
(66,5-69,7)\end{array}$ & $\begin{array}{c}92,8 \\
(91,9-93,7)\end{array}$ & $\begin{array}{c}67,3 \\
(65,7-68,9)\end{array}$ & $\begin{array}{c}94,2 \\
(93,4-95,0)\end{array}$ & $\begin{array}{c}32,0 \\
(30,4-33,6)\end{array}$ & $\begin{array}{c}81,9 \\
(80,6-83,2)\end{array}$ & $\begin{array}{c}67,1 \\
(65,5-68,7)\end{array}$ & $\begin{array}{c}95,7 \\
(95,0-96,4)\end{array}$ \\
\hline & $\begin{array}{l}50.001 \mathrm{a} \\
100.000^{(\mathrm{i})}\end{array}$ & $\begin{array}{c}69,2 \\
(67,0-71,4)\end{array}$ & $\begin{array}{c}92,4 \\
(91,1-93,7)\end{array}$ & $\begin{array}{c}67,2 \\
(64,9-69,5)\end{array}$ & $\begin{array}{c}94,0 \\
(92,9-95,1)\end{array}$ & $\begin{array}{c}33,5 \\
(31,2-35,8)\end{array}$ & $\begin{array}{c}81,6 \\
(79,7-83,5)\end{array}$ & $\begin{array}{c}67,7 \\
(65,5-69,9)\end{array}$ & $\begin{array}{c}94,9 \\
(93,8-96,0)\end{array}$ \\
\hline & $\begin{array}{l}100.000 \text { ou } \\
\text { mais }^{(j)}\end{array}$ & $\begin{array}{c}81,4 \\
(80,4-82,4)\end{array}$ & $\begin{array}{c}87,7 \\
(86,8-88,6)\end{array}$ & $\begin{array}{c}76,5 \\
(75,4-77,6)\end{array}$ & $\begin{array}{c}92,7 \\
(92,0-93,4)\end{array}$ & $\begin{array}{c}54,6 \\
(53,3-55,9)\end{array}$ & $\begin{array}{c}79,5 \\
(78,4-80,6)\end{array}$ & $\begin{array}{c}82,2 \\
(81,2-83,2)\end{array}$ & $\begin{array}{c}89,7 \\
(88,9-90,5)\end{array}$ \\
\hline & Brasil $^{(\mathrm{k})}$ & $\begin{array}{c}70,3 \\
(69,6-71,0)\end{array}$ & $\begin{array}{c}90,1 \\
(89,6-90,6)\end{array}$ & $\begin{array}{c}68,7 \\
(68,0-69,4)\end{array}$ & $\begin{array}{c}93,7 \\
(93,3-94,1)\end{array}$ & $\begin{array}{c}38,0 \\
(37,2-38,8)\end{array}$ & $\begin{array}{c}80,3 \\
(79,7-80,9)\end{array}$ & $\begin{array}{c}73,0 \\
(72,3-73,7)\end{array}$ & $\begin{array}{c}93,0 \\
(92,6-93,4)\end{array}$ \\
\hline
\end{tabular}

* valor de p $<0,001$ (razão de verossimilhança). ${ }^{(\mathrm{a})} n=908 ;{ }^{(\mathrm{b})} n=5.096 ;{ }^{(\mathrm{c})} n=5.723 ;{ }^{(\mathrm{d})} n=2.600 ;{ }^{(\mathrm{e})} n=1.051 ;{ }^{(\mathrm{f})} n=2.237 ;{ }^{(\mathrm{g})} n=2.466 ;{ }^{(\mathrm{h})} n=3.363 ;{ }^{(\mathrm{i})} n=$ $1.670 ;{ }^{(j)} n=5.516 ;^{(k)} n=15.378$.

Fonte: Elaborado pelos autores.

para 80,3\% (Tabela 1). Ainda na mesma temática, quando questionados sobre o acolhimento na unidade de saúde, os profissionais indicaram que, em 2012, 73\% das equipes se organizavam para acolher situações de urgência e emergência, passando para 93\% em 2018 (Tabela 1).

No que diz respeito aos dias e horários de funcionamento das UBS, também foram observadas melhorias, exceto para o funcionamento em horário de almoço. Em 2018, 97,5\% das UBS funcionavam cinco ou mais dias da semana, 96,7\% funcionavam ao menos dois turnos por dia e apenas 50,5\% funcionavam em horário de almoço. Não há variação expressiva entre as regiões e municípios de diferentes portes no que se refere aos dias e turnos de funcionamento, porém, para o funcionamento em horário de almoço, foram no Sudeste e maiores municípios que se pode observar proporções mais elevadas (Tabela 2).

Quanto à organização da agenda das equipes, de acordo com os profissionais, o percentual de usuários que conseguiam sair da unidade com consulta agendada, quando não havia necessidade de atendimento no mesmo dia, cresceu de $83,5 \%$ para $91,4 \%$, com aumento mais marcado no Sul e Centro-Oeste (Tabela 2). Aumento importante também ocorreu na proporção de equipes que realizam renovação de receitas para usuários de cuidado continuado sem a necessidade de consultas médicas $(28,4 \%)$. A agenda aberta para que os usuários possam buscar e mostrar os resultados dos exames também apresentou me- 
lhoria acentuada, saindo de $48,6 \%$ para $95,4 \%$ (Tabela 2).

Quando se trata do tempo de espera entre o momento em que os usuários buscam o atendimento e conseguem efetivá-lo, houve pequena melhoria no percentual de equipes que asseguram a usuários com hipertensão e diabetes o agendamento de sua primeira consulta com tempo de espera máximo de até sete dias, variando para ambos os casos de, aproximadamente, $82 \%$ para $87 \%$, e apenas para as equipes do Norte que não se constatou melhoria (Tabela 2).

De acordo com os usuários, houve ligeira melhora no número de unidades que funcionam cinco ou mais dias de semana e se manteve praticamente estável o número de unidades que funcionam ao menos dois turnos por dia. Quando questionados sobre se o horário de funcionamento das UBS atende às suas necessidades, não houve melhoria observada. No entanto, a maior parte dos usuários afirmou que sim em ambos os momentos avaliados e são nas grandes cidades que eles apontam para uma maior insatisfação nesse quesito (Tabela 3 ).

Para a subdimensão organização da agenda, embora os resultados tenham demonstrado melhorias, o cenário geral ainda aponta para a existência de significativas barreiras para o acesso. Em 2012, apenas 19,3\% dos usuários relataram que era possível realizar agendamento de consultas todos os dias da semana em qualquer horário durante o funcionamento da UBS, atingindo 58,1\% em 2018 (Tabela 3).

Ainda sobre a marcação de consultas, em 2018, apenas $19,7 \%$ informaram que os atendimentos são realizados com horário pré-definido, porcentagem inferior àquela verificada em 2012 $(26,9 \%)$. As diferenças entre as regiões e portes

Tabela 2. Dias e horários de funcionamento e organização da agenda, segundo profissionais de saúde, por grande região e porte populacional, Brasil, 2012 e 2018.

\begin{tabular}{|c|c|c|c|c|c|c|c|c|}
\hline \multirow{4}{*}{$\begin{array}{c}\text { Subdimensão } \\
\text { Variáveis }\end{array}$} & \multicolumn{6}{|c|}{ Dias e horários de funcionamento } & \multirow{2}{*}{\multicolumn{2}{|c|}{$\begin{array}{c}\text { Organização da agenda } \\
\text { Realiza agendamento } \\
\text { quando não precisa } \\
\text { atendimento no mesmo dia }\end{array}$}} \\
\hline & \multicolumn{2}{|c|}{$\begin{array}{c}\text { Funciona } 5 \text { ou mais dias } \\
\text { da semana }{ }^{\star}\end{array}$} & \multicolumn{2}{|c|}{$\begin{array}{l}\text { Funciona ao menos } 2 \\
\text { turnos por dia }\end{array}$} & \multicolumn{2}{|c|}{$\begin{array}{l}\text { Funciona no horário do } \\
\text { almoço }(12 \mathrm{~h} \text { às } 14 \mathrm{~h})^{*}\end{array}$} & & \\
\hline & & & & & & & 2012 & \\
\hline & & & & & & & & \\
\hline \multicolumn{9}{|l|}{ Região } \\
\hline & $8,9)$ & $\begin{array}{r}98 \\
(98,2-\end{array}$ & $2,5)$ & $\begin{array}{c}96,5 \\
(95,3-97,7)\end{array}$ & $\begin{array}{r}5 \\
(48,4\end{array}$ & $77,7)$ & $\begin{array}{c}80,8 \\
(78,2-83,4)\end{array}$ & $\begin{array}{c}87,2 \\
(85,0-89,4)\end{array}$ \\
\hline Nordeste $^{(b)}$ & $\begin{array}{c}91,8 \\
(91,0-92,6)\end{array}$ & $\begin{array}{c}97,0 \\
(96,5-97,5)\end{array}$ & $\begin{array}{c}82,1 \\
(81,0-83,2)\end{array}$ & $\begin{array}{c}94,3 \\
(93,7-94,9)\end{array}$ & $\begin{array}{c}34,1 \\
(32,8-35,4)\end{array}$ & $\begin{array}{c}37,3 \\
(36,0-38,6)\end{array}$ & $\begin{array}{c}85,2 \\
(84,2-86,2)\end{array}$ & $\begin{array}{c}92,4 \\
(91,7-93,1)\end{array}$ \\
\hline Sude & $\begin{array}{c}96,2 \\
(95,7-96,7)\end{array}$ & $\begin{array}{c}97,2 \\
(96,8-97,6)\end{array}$ & $\begin{array}{c}95,7 \\
(95,2-96,2)\end{array}$ & $\begin{array}{c}97,7 \\
(97,3-98,1)\end{array}$ & $\begin{array}{c}79,6 \\
(78,6-80,6)\end{array}$ & $\begin{array}{c}75,7 \\
(74,6-76,8)\end{array}$ & $\begin{array}{c}88,5 \\
(87,7-89,3)\end{array}$ & $\begin{array}{c}92,3 \\
(91,6-93,0)\end{array}$ \\
\hline $\mathrm{Su}$ & $\begin{array}{c}97,5 \\
(96,9-98,1)\end{array}$ & $\begin{array}{c}98,2 \\
(97,7-98,7)\end{array}$ & $\begin{array}{c}92,4 \\
(91,4-93,4)\end{array}$ & $\begin{array}{c}98,8 \\
(98,4-99,2)\end{array}$ & $\begin{array}{c}34,5 \\
(32,7-36,3)\end{array}$ & $\begin{array}{c}30,2 \\
(28,4-32,0)\end{array}$ & $\begin{array}{c}74,4 \\
(72,7-76,1)\end{array}$ & $\begin{array}{c}90,2 \\
(89,1-91,3)\end{array}$ \\
\hline Cen & $\begin{array}{c}97,0 \\
(96,0-98,0)\end{array}$ & $\begin{array}{c}98,9 \\
(98,3-99,5)\end{array}$ & $\begin{array}{c}94,0 \\
(92,6-95,4)\end{array}$ & $\begin{array}{c}98,5 \\
(97,8-99,2)\end{array}$ & $\begin{array}{c}42,7 \\
(39,7-45,7)\end{array}$ & $\begin{array}{c}32,7 \\
(29,9-35,5)\end{array}$ & $\begin{array}{c}72,3 \\
(69,6-75,0)\end{array}$ & $\begin{array}{c}88,2 \\
(86,2-90,2)\end{array}$ \\
\hline \multicolumn{9}{|l|}{ Porte Populacional } \\
\hline & $\begin{array}{c}94,3 \\
(93,3-95,3)\end{array}$ & $\begin{array}{c}98,2 \\
(97,6-98,8)\end{array}$ & $\begin{array}{c}89,1 \\
(87,8-90,4)\end{array}$ & $\begin{array}{c}98,2 \\
(97,6-98,8)\end{array}$ & $\begin{array}{c}47,3 \\
(45,2-49,4)\end{array}$ & $\begin{array}{c}42,0 \\
(40,0-44,0)\end{array}$ & $\begin{array}{c}78,6 \\
(76,9-80,3)\end{array}$ & $\begin{array}{c}91,0 \\
(89,8-92,2)\end{array}$ \\
\hline & $\begin{array}{r}93,2 \\
(92,2-94\end{array}$ & $\begin{array}{c}98,3 \\
(97,8-98,8)\end{array}$ & $\begin{array}{c}84,9 \\
(83,5-86,3)\end{array}$ & $\begin{array}{c}97,7 \\
(97,1-98\end{array}$ & $\begin{array}{c}42,8 \\
(40,8-44,8)\end{array}$ & $\begin{array}{c}42,0 \\
(40,1-43,9)\end{array}$ & $\begin{array}{c}84,1 \\
(82,7-85,5)\end{array}$ & $\begin{array}{c}92,7 \\
(91,7-93,7)\end{array}$ \\
\hline $\begin{array}{l}20.001 \mathrm{a} \\
50.000^{(\mathrm{h})}\end{array}$ & $\begin{array}{c}94,3 \\
(93,5-95,1)\end{array}$ & $\begin{array}{c}99,2 \\
(98,9-99,5)\end{array}$ & $\begin{array}{c}87,9 \\
(86,8-89,0)\end{array}$ & $\begin{array}{c}97,9 \\
(97,4-98,4)\end{array}$ & $\begin{array}{c}46,1 \\
(44,4-47,8)\end{array}$ & $\begin{array}{c}44,1 \\
(42,4-45,8)\end{array}$ & $\begin{array}{c}84,6 \\
(83,4-85,8)\end{array}$ & $\begin{array}{c}94,9 \\
(94,2-95,6)\end{array}$ \\
\hline $\begin{array}{l}50.001 \mathrm{a} \\
100.000^{(\mathrm{i})}\end{array}$ & $\begin{array}{c}96,5 \\
(95,6-97,4)\end{array}$ & $\begin{array}{c}98,7 \\
(98,2-99,2)\end{array}$ & $\begin{array}{c}89,7 \\
(88,2-91,2)\end{array}$ & $\begin{array}{c}98,5 \\
(97,9-99,1)\end{array}$ & $\begin{array}{c}47,3 \\
(44,9-49,7)\end{array}$ & $\begin{array}{c}43,9 \\
(41,5-46,3)\end{array}$ & $\begin{array}{c}82,4 \\
(80,6-84,2)\end{array}$ & $\begin{array}{c}93,6 \\
(92,4-94,8)\end{array}$ \\
\hline $\begin{array}{l}100.000 \text { ou } \\
\text { mais }^{(j)}\end{array}$ & $\begin{array}{c}96,5 \\
(96,0-97,0)\end{array}$ & $\begin{array}{c}95,4 \\
(94,8-96,0)\end{array}$ & $\begin{array}{c}95,0 \\
(94,4-95,6)\end{array}$ & $\begin{array}{c}94,7 \\
(97,1-95,3)\end{array}$ & $\begin{array}{c}65,9 \\
(64,6-67,2)\end{array}$ & $\begin{array}{c}63,4 \\
(62,1-64,7)\end{array}$ & $\begin{array}{c}84,8 \\
(83,9-85,7)\end{array}$ & $\begin{array}{c}88,7 \\
(87,9-89,5)\end{array}$ \\
\hline $\operatorname{Brasil}^{(\mathrm{k})}$ & $\begin{array}{c}95,1 \\
(94,8-95,4)\end{array}$ & $\begin{array}{c}97,5 \\
(97,3-97,7)\end{array}$ & $\begin{array}{c}90,3 \\
(89,8-90,8)\end{array}$ & $\begin{array}{c}96,7 \\
(96,4-97,0)\end{array}$ & $\begin{array}{c}53,0 \\
(52,2-53,8)\end{array}$ & $\begin{array}{c}50,5 \\
(49,7-51,3)\end{array}$ & $\begin{array}{c}83,5 \\
(82,9-84,1)\end{array}$ & $\begin{array}{c}91,4 \\
(91,0-91,8)\end{array}$ \\
\hline
\end{tabular}




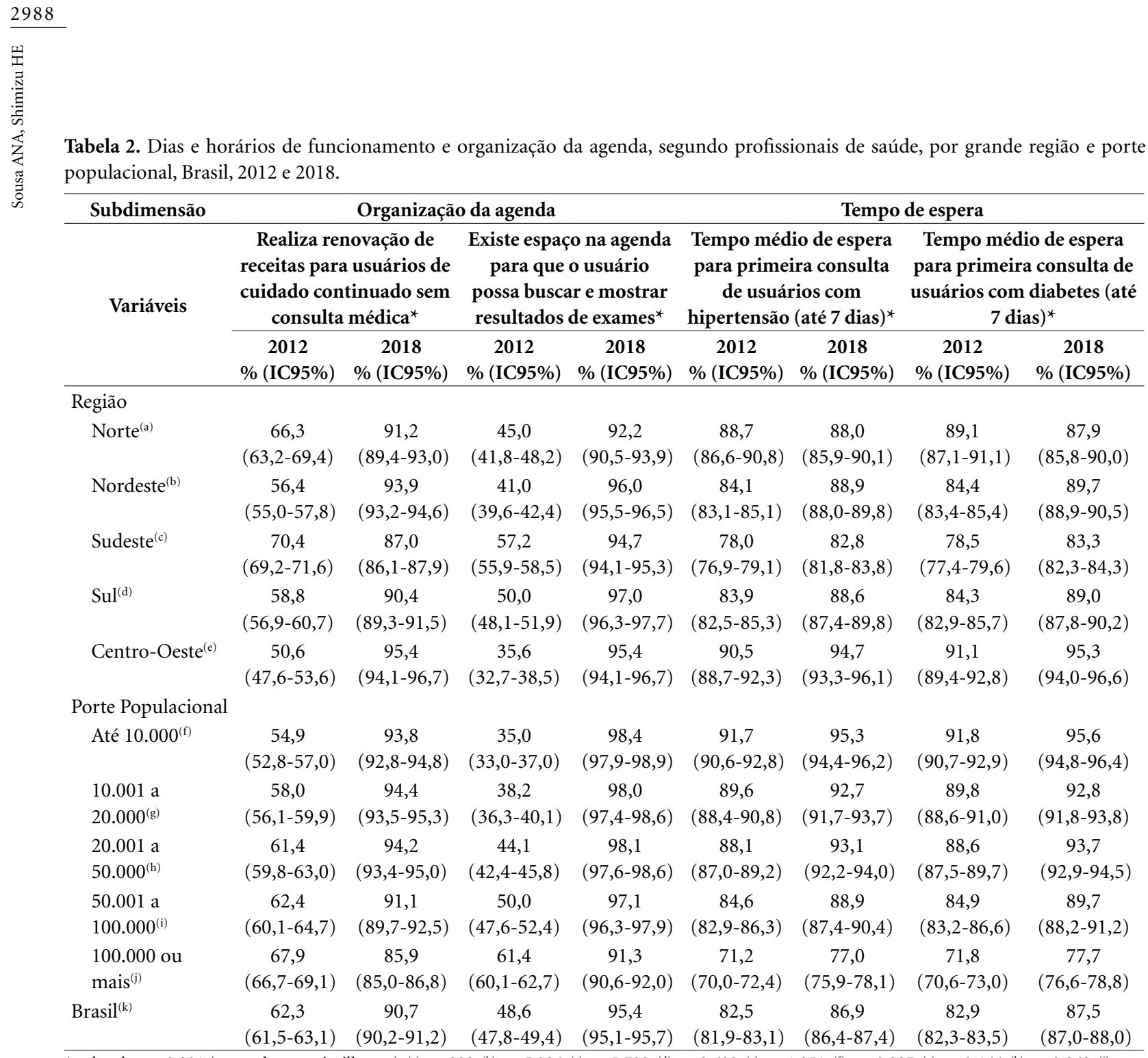

${ }^{*}$ valor de $\mathrm{p}<0,001$ (razão de verossimilhança). ${ }^{(\mathrm{a})} n=908 ;{ }^{(\mathrm{b})} n=5.096 ;{ }^{(\mathrm{c})} n=5.723 ;{ }^{(\mathrm{d})} n=2.600 ;{ }^{(\mathrm{e})} n=1.051 ;{ }^{(\mathrm{f})} n=2.237 ;{ }^{\text {(g) }} n=2.466 ;{ }^{(\mathrm{l})} n=3.363 ;{ }^{(\mathrm{i})} n=$ $1.670 ;{ }^{(\mathrm{j})} n=5.516 ;{ }^{(\mathrm{k})} n=15.378$.

Fonte: $\mathrm{PMAQ} / \mathrm{DAB} / \mathrm{MS}$.

populacionais para essa questão é bastante acentuada. Enquanto no Nordeste praticamente a totalidade $(96,2 \%)$ dos usuários informou não conseguir agendar consultas com horário marcado, no Sudeste esse percentual é de 67,5\% (Tabela 3). Na questão que se refere à organização das equipes para permitir que usuários possam falar com os profissionais de saúde em caso de dúvidas após as consultas, verifica-se que houve aumento de $80,2 \%$ para $87,9 \%$, sem diferenças que chamem a atenção entre as regiões ou municípios de distintos portes (Tabela 3).

Quando questionados sobre elementos relacionadas ao acolhimento, os usuários também indicam que houve melhora nos serviços de $\mathrm{AB}$. Em 2012, 79,1\% informaram que conseguiam ser escutados ao procurarem a UBS sem que tivessem consulta agendada e em 2018 esse valor aumentou para $84,2 \%$. A proporção de usuários que avaliaram positivamente o modo como são acolhidos nas unidades básicas aumentou quase $20 \%$, de $66,4 \%$ para $85,8 \%$. A região Sul e os menores municípios abrigam os usuários mais satisfeitos com a maneira na qual os profissionais os acolhem (Tabela 4).

Ao serem indagados se buscaram a UBS da última vez que tiveram algum problema de urgência, $57,7 \%$ dos usuários que passaram por alguma situação de urgência afirmaram que sim em 2012 e 64,7\% em 2018. Não foram encontradas diferenças por região, mas quando se observa por tamanho do município, a proporção de usu- 
Tabela 3. Dias e horários de funcionamento e organização da agenda, segundo usuários, por grande região e porte populacional, Brasil, 2012 e 2018.

\begin{tabular}{|c|c|c|c|c|c|c|}
\hline \multirow{3}{*}{$\begin{array}{c}\text { Subdimensão } \\
\text { Variáveis }\end{array}$} & \multicolumn{6}{|c|}{ Dias e horários de funcionamento } \\
\hline & \multicolumn{2}{|c|}{$\begin{array}{l}\text { Funciona } 5 \text { ou mais dias da } \\
\text { semana }^{\star}\end{array}$} & \multicolumn{2}{|c|}{$\begin{array}{l}\text { Funciona ao menos } 2 \text { turnos } \\
\text { por } \mathrm{dia}^{\star}\end{array}$} & \multicolumn{2}{|c|}{$\begin{array}{c}\text { O horário de funcionamento da } \\
\text { UBS atende às necessidades do } \\
\text { usuário* }\end{array}$} \\
\hline & $\begin{array}{c}2012 \\
\%(\mathrm{IC} 95 \%)\end{array}$ & $\begin{array}{c}2018 \\
\%(\mathrm{IC} 95 \%)\end{array}$ & $\begin{array}{c}2012 \\
\%(\mathrm{IC} 95 \%)\end{array}$ & $\begin{array}{c}2018 \\
\%(\mathrm{IC} 95 \%)\end{array}$ & $\begin{array}{c}2012 \\
\%(\mathrm{IC} 95 \%)\end{array}$ & $\begin{array}{c}2018 \\
\%(\mathrm{IC} 95 \%)\end{array}$ \\
\hline \multicolumn{7}{|l|}{ Região } \\
\hline Norte $^{(\mathrm{a})}$ & $91,8(90,9-92,7)$ & $93,4(92,5-94,3)$ & $87,5(86,4-88,6)$ & $88,4(87,3-89,5)$ & $81,6(80,3-82,9)$ & $80,1(78,7-81,5)$ \\
\hline Nordeste $^{(\mathrm{b})}$ & $89,8(89,4-90,2)$ & $93,6(93,2-94,0)$ & $89,3(88,9-89,7)$ & $90,4(90,0-90,8)$ & $84,8(84,3-85,3)$ & $85,4(84,9-85,9)$ \\
\hline Sudeste ${ }^{(c)}$ & $96,1(95,8-96,4)$ & $96,9(96,7-97,1)$ & $96,2(96,0-96,4)$ & $95,0(94,7-95,3)$ & $87,2(86,8-87,6)$ & $85,7(85,2-86,2)$ \\
\hline $\mathrm{Sul}^{(\mathrm{d})}$ & $94,9(94,5-95,3)$ & $96,4(96,0-96,8)$ & $95,8(95,4-96,2)$ & $95,4(95,0-95,8)$ & $86,3(85,6-87,0)$ & $86,4(85,7-87,1)$ \\
\hline Centro-Oeste ${ }^{(e)}$ & $3,5(92,7-94,3)$ & $94,9(94,2-95,6)$ & $95,0(94,3-95,7)$ & $93,9(93,2-94,6)$ & $85,9(84,8-87,0)$ & $85,3(84,2-86,4)$ \\
\hline \multicolumn{7}{|l|}{ Porte Populacional } \\
\hline Até $10.000^{(\mathrm{f})}$ & $93,4(92,9-93,9)$ & $95,3(94,9-95,7)$ & $90,7(90,1-91,3)$ & $87,9(87,2-88,6)$ & $89,3(88,7-89,9)$ & $88,9(88,2-89,6)$ \\
\hline 10.001 a $20.000^{(\mathrm{g})}$ & $91,0(90,4-91,6)$ & $94,4(93,9-94,9)$ & $90,8(90,2-91,4)$ & $92,3(91,8-92,8)$ & $87,6(86,9-88,3)$ & $87,7(87,0-88,4)$ \\
\hline 20.001 a $50.000^{(\mathrm{h})}$ & $92,9(92,5-93,3)$ & $95,5(95,1-95,9)$ & $92,6(92,2-93,0)$ & $94,2(93,8-94,6)$ & $86,4(85,8-87,0)$ & $87,2(86,6-87,8)$ \\
\hline 50.001 a $100.000^{(\mathrm{i})}$ & $94,3(93,7-94,9)$ & $96,1(95,6-96,6)$ & $94,7(94,2-95,2)$ & $95,4(94,9-95,9)$ & $87,3(86,5-88,1)$ & $84,7(83,8-85,6)$ \\
\hline 100.000 ou mais ${ }^{(j)}$ & $94,5(94,2-94,8)$ & $95,8(95,5-96,1)$ & $95,5(95,2-95,8)$ & $94,5(94,2-94,8)$ & $82,8(82,3-83,3)$ & $81,9(81,4-82,4)$ \\
\hline Brasil $^{(\mathrm{k})}$ &, $4(93,2-93,6)$ & $95,4(95,2-95,6)$ & $93,3(93,1-93,5)$ & $93,1(92,9-93,3)$ & $85,9(85,6-86,2)$ & $85,4(85,1-85,7)$ \\
\hline & \multicolumn{6}{|c|}{ Organização da agenda } \\
\hline Variáveis & \multicolumn{2}{|c|}{$\begin{array}{c}\text { Agendamento de consulta todos } \\
\text { os dias da semana em qualquer } \\
\text { horário }^{\star}\end{array}$} & \multicolumn{2}{|c|}{ Consulta com hora marcada ${ }^{\star}$} & \multicolumn{2}{|c|}{$\begin{array}{l}\text { Encontra facilidade para falar } \\
\text { com profissionais em caso de } \\
\text { dúvidas após a consulta }^{\star(1) ;(\mathrm{m})}\end{array}$} \\
\hline & $\begin{array}{c}2012 \\
\%(\mathrm{IC} 95 \%)\end{array}$ & $\begin{array}{c}2018 \\
\%(\mathrm{IC} 95 \%)\end{array}$ & $\begin{array}{c}2012 \\
\%(\mathrm{IC} 95 \%)\end{array}$ & $\begin{array}{c}2018 \\
\%(\mathrm{IC} 95 \%)\end{array}$ & $\begin{array}{c}2012 \\
\%(\mathrm{IC} 95 \%)\end{array}$ & $\begin{array}{c}2018 \\
\%(\mathrm{IC} 95 \%)\end{array}$ \\
\hline \multicolumn{7}{|l|}{ Região } \\
\hline Norte $^{(a)}$ & $9,9(8,9-10,9)$ & $51,5(49,7-53,3)$ & $18,5(17,2-19,8)$ & $7,1(6,2-8,0)$ & $72,4(70,9-73,9)$ & $83,1(81,8-84,4)$ \\
\hline Nordeste $^{(\mathrm{b})}$ & $12,4(11,9-12,9)$ & $53,2(52,5-53,9)$ & $7,3(6,9-7,7)$ & $3,8(3,5-4,1)$ & $81,1(80,6-81,6)$ & $90,2(89,8-90,6)$ \\
\hline Sudeste ${ }^{(c)}$ & $24,5(23,9-25,1)$ & $59,3(58,6-60,0)$ & $43,7(43,1-44,3)$ & $32,5(31,9-33,1)$ & $80,9(80,4-81,4)$ & $87,1(86,6-87,6)$ \\
\hline $\mathrm{Sul}^{(\mathrm{d})}$ & $23,8(22,9-24,7)$ & $65,1(64,2-66,0)$ & $33,9(33,0-34,8)$ & $30,5(29,6-31,4)$ & $80,1(79,3-80,9)$ & $87,0(86,3-87,7)$ \\
\hline Centro-Oeste ${ }^{(e)}$ & $20,4(19,2-21,6)$ & $62,2(60,7-63,7)$ & $17,0(15,8-18,2)$ & $8,4(7,5-9,3)$ & $77,2(75,9-78,5)$ & $87,6(86,6-88,6)$ \\
\hline \multicolumn{7}{|l|}{ Porte Populacional } \\
\hline Até $10.000^{(\mathrm{f})}$ & $23,6(22,7-24,5)$ & $69,1(68,1-70,1)$ & $12,9(12,2-13,6)$ & $10,5(9,9-11,1)$ & $83,7(82,9-84,5)$ & $90,2(89,6-90,8)$ \\
\hline $10.001 \mathrm{a} 20.000^{(\mathrm{g})}$ & $20,0(19,2-20,8)$ & $62,3(61,3-63,3)$ & $12,9(12,2-13,6)$ & $10,0(9,4-10,6)$ & $82,8(82,1-83,5)$ & $90,0(89,4-90,6)$ \\
\hline 20.001 a $50.000^{(\mathrm{h})}$ & $17,7(17,0-18,4)$ & $59,6(58,7-60,5)$ & $16,4(15,8-17,0)$ & $11,9(11,3-12,5)$ & $81,7(81,0-82,4)$ & $90,0(89,5-90,5)$ \\
\hline 50.001 a $100.000^{(\mathrm{i})}$ & $17,2(16,3-18,1)$ & $54,4(53,2-55,6)$ & $21,6(20,6-22,6)$ & $15,6(14,7-16,5)$ & $80,2(79,2-81,2)$ & $87,2(86,4-88,0)$ \\
\hline 100.000 ou mais ${ }^{(j)}$ & $18,9(18,4-19,4)$ & $51,5(50,8-52,2)$ & $47,5(46,8-48,2)$ & $35,1(34,4-35,8)$ & $76,6(76,0-77,2)$ & $84,7(84,2-85,2)$ \\
\hline Brasil $^{(\mathrm{k})}$ & $19,3(19,0-19,6)$ & $58,1(57,7-58,5)$ & $26,9(26,5-27,3)$ & $19,7(19,4-20,0)$ & $80,2(79,9-80,5)$ & $87,9(87,6-88,2)$ \\
\hline
\end{tabular}

* valor de p < 0,001 (razão de verossimilhança). ${ }^{\text {(a) }} 2012=3.231 / 2018=3.049 ;{ }^{\text {(b) }} 2012=19.653 / 2018=18.427$; $^{\text {(c) }} 2012=22.870 / 2018=21.193 ;$ (d) $2012=9.560 / 2018=9.689 ;^{(\mathrm{e})} 2012=4.040 / 2018=4.011 ;^{\text {(f) }^{\mathrm{f}}} 2012=8.813 / 2018=8.650$ ( $^{\text {(g) }} 2012=9.834 / 2018=9.282{ }^{\text {(h) }} 2012=13.055 / 2018=$ $12.558 ;^{(i)} 2012=6.580 / 2018=6.311{ }^{(j)} 2012=21.072 / 2018=19.568 ;{ }^{(k)} 2012=59.354 / 2018=56.369 ;{ }^{(1)}$ Foram desconsiderados os usuários que afirmaram que não precisaram tirar dúvidas $(2012=16.051$ casos; $2018=12.771$ casos $)$; ${ }^{(\mathrm{m})}$ Foram consideradas as respostas sempre e na maioria das vezes.

Fonte: PMAQ/DAB/MS.

ários que procuraram atendimento de urgência na unidade varia de $76,7 \%$ nos menores a $58,8 \%$ nos maiores. Por sua vez, entre aqueles que procuraram a unidade quando tiveram alguma necessidade de urgência, $82,8 \%$ disseram que conseguiram atendimento sem ter hora marcada em
2012 e 88,6\% em 2018. Ainda entre esses mesmos usuários, 69,5\% afirmaram que o tempo de espera para serem atendidos foi de até 30 minutos em 2012, com uma ligeira variação para 67,3\% em 2018 (Tabela 4). 
Tabela 4. Acolhimento à demanda espontânea, segundo usuários, por grande região e porte populacional, Brasil, 2012 e 2018.

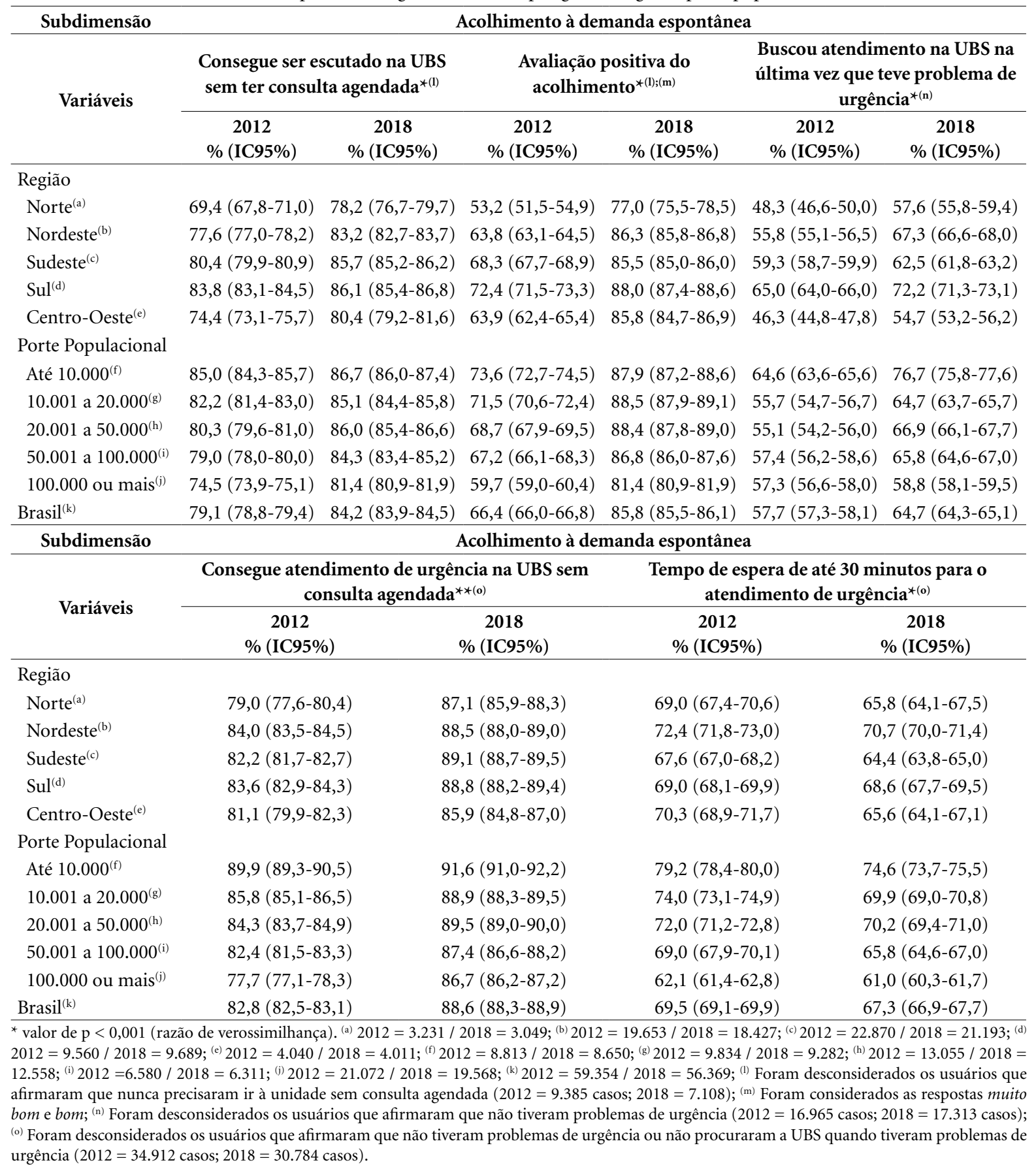

Fonte: PMAQ/DAB/MS.

\section{Discussão}

Verificou-se que os esforços empreendidos nos últimos anos para o aumento das coberturas foram capazes de produzir bons resultados, na medida em que segue crescendo a oferta de serviços de $\mathrm{AB}$ nos diferentes contextos regionais do país, entretanto, ainda persistem expressivos contingentes populacionais não cobertos pela $\mathrm{AB}$, havendo ainda cerca de um quarto da população brasileira sem ter um serviço de referência ${ }^{5}$. O Sudeste é a região que apresenta as mais baixas coberturas populacionais e, muito embora o Norte tenha apresentando o maior aumento 
relativo para o período estudado, segue como a região que encontra os maiores desafios para o alcance de populações dispersas que demandam modos diversificados de organização dos serviços para atender suas especificidades ${ }^{18}$.

Como aponta a literatura, a continuidade da expansão das coberturas depende, entre outras coisas, do aumento da destinação de orçamento público, sobretudo do Governo Federal, que no período mais recente tem diminuído sua participação relativa no financiamento da $\mathrm{AB}$ e do equacionamento da escassez médica, principalmente nas regiões mais isoladas e empobrecidas das grandes cidades ${ }^{6,19}$.

No que diz respeito à estrutura física e arquitetônica para assegurar o acesso aos usuários com restrições de mobilidade, importantes avanços foram observados com transformações em entradas e ambientes internos das UBS para permitir o livre trânsito de cadeirantes. Contudo, ainda há significativo número de unidades com necessidade de adequações, em torno de um terço delas não há corredores e portas internas adaptadas para cadeiras de rodas. Na mesma direção, estudo realizado em dois grandes municípios da Bahia demonstrou haver problemas relacionados à adaptação da grande maioria de suas unidades para se ajustarem à demanda de indivíduos com restrição de mobilidade ${ }^{20}$. Os resultados aqui apresentados apontam para o desafio e a necessidade de maiores intervenções no sentido de evitar que estruturas arquitetônicas se apresentem como obstáculos que impeçam o acesso de usuários.

Ao analisarmos os dados referentes aos dias e horários de funcionamento das UBS, notamos que, de maneira geral, profissionais e usuários indicam que a maior parte delas funcionam o mínimo recomendado, ou seja, dois turnos em cinco dias da semana, seja qual for o cenário. Mas quando se trata do funcionamento em horário de almoço (12h às $14 \mathrm{~h})$, metade das unidades não oferece acesso aos usuários, comprometendo a possibilidade de utilização para uma parcela da população que, muitas vezes, o horário do almoço é a melhor ou única alternativa para buscar o serviço. São nas cidades mais populosas que se encontram usuários mais insatisfeitos $(18,1 \%)$ quanto aos horários em que as unidades estão abertas. Estudo realizado em Salvador (BA) encontrou resultados similares para satisfação com horários de funcionamento por parte dos usuários, com 16,3\% dos entrevistados afirmando não se sentirem atendidos com os horários disponíveis ${ }^{8}$. Principalmente nas maiores cidades, contextos nos quais trabalhadores despendem maior tempo para se deslocarem até o trabalho, a oferta de serviços em horário estendido e aos finais de semana podem representar importante estratégia para assegurar maior acesso a esses usuários, sobretudo em áreas de abrangência constituídas por indivíduos de mais baixa renda que, em geral, são aqueles com maior propensão a estarem em situação de trabalho precarizada ou fragilizada.

Os dados do PMAQ revelaram que ao longo dos anos 2010 houve expressivo aumento do número de equipes que se dedicaram a implantar e qualificar o processo de acolhimento em suas unidades. Para todos os contextos, a grande maioria das equipes incorporou algum mecanismo de acolhimento, no entanto, os dados também demonstraram alguns elementos que apontam para os limites no modo como ele tem sido implantando.

Boas práticas de acolhimento exigem que ele seja realizado durante todo o período de funcionamento do serviço e que oferte atendimento de urgência e emergência, e para ambos os quesitos notou-se que cerca de $10 \%$ das unidades não oferecem acolhimento por todo o período em que estão abertas e não atendem situações de urgência. Ainda persistem práticas como a realização do acolhimento apenas no início do turno, forçando usuários a terem que chegar mais cedo para serem acolhidos. Estudo realizado em UBS de uma grande cidade do estado de São Paulo ${ }^{10}$ e outro realizado em 3 capitais do Nordeste ${ }^{11}$ demonstram a dificuldade dos usuários em conseguirem ser acolhidos se não se organizam ou não encontram meios para chegar na unidade mais cedo.

Um importante indicador sobre a qualidade do acolhimento praticado é a existência de protocolos que orientem as ações que devem ser desenvolvidas no contato com os usuários. Entre outras coisas, é no momento do acolhimento que profissionais devem atuar e esclarecer os usuários sobre a possibilidade de diferentes tempos de espera e de manejo de cada caso, considerando o processo de avaliação de risco e vulnerabilidade. Como vimos, cerca de um quinto das equipes analisadas não possuem protocolos de acolhimento, sendo que no Norte a proporção é de quase a metade delas. Esses números indicam a necessidade de maior investimento em iniciativas que impulsionem o aperfeiçoamento do acolhimento, tanto do ponto de vista organizativo, quanto na perspectiva da qualificação de práticas clínicas. 
Como aponta a literatura, a qualidade do acesso está fortemente associada à capacidade dos serviços em desenvolver boas práticas de acolhimento à demanda espontânea, reduzindo filas e tempo de espera e se baseando em critérios de risco. Esse dispositivo favorece o reconhecimento dos grupos mais vulneráveis e mais expostos a fatores de risco e, a partir desse reconhecimento, também favorece a reorganização dos serviços na direção de garantir um acesso mais adequado à necessidade de cada usuário. Com um bom acolhimento, os usuários passam a estabelecer outro tipo de relacionamento com a UBS, reconhecendo nela também um espaço para a resolução de problemas imediatos de saúde ${ }^{21}$.

No que se refere à percepção dos usuários sobre a temática do acolhimento, embora quase a totalidade $(96,4 \%)$ dos profissionais tenham afirmado haver acolhimento em suas equipes, $15,8 \%$ indicaram que não conseguem ser escutados ao buscarem a UBS sem ter consulta agendada, revelando um certo descolamento entre o que os profissionais entendem por acolhimento e como os usuários o experimentam. Uma boa maneira de avaliar se o acolhimento é capaz de alargar ou se, ao contrário, opera como fator de estreitamento "das portas" da UBS é se os usuários, quando necessitam do serviço de saúde em situação de urgência, buscam a unidade. Muito embora tenha havido melhoria, mais de um terço dos usuários que relataram terem tido alguma urgência não buscaram a sua unidade básica de referência, alternativamente, procuraram unidades de pronto atendimento, hospitais ou clínicas.

Entre os motivos para explicar a procura por outros serviços foram apontados: porque necessitava chegar cedo, porque a unidade não atende urgência ou não havia profissional. Essa proporção se eleva na medida que aumenta o porte populacional do município, chegando a ser maior do que $40 \%$ nas cidades acima de 100 mil habitantes. Quanto a esse fenômeno, uma hipótese a ser verificada é a de que nas cidades menores, em muitas situações, a UBS é a única oferta disponível para os usuários, em contraste com as grandes cidades que possuem redes de urgência mais estruturadas que competem com os serviços básicos de saúde, como Unidades de Pronto Atendimento (UPA) e hospitais de pronto-socorro. Numa grande cidade paulista, pesquisa com usuários mostrou maior disposição para procurar hospitais em casos mais urgentes, reconhecendo a UBS como o espaço para resolver questões tidas como "mais simples", reforçando a ideia predominante de que a $\mathrm{AB}$ se ocupa de necessidades e problemas menos relevantes e que possui menor capacidade de resolver as demandas dos usuários ${ }^{10}$.

Um percentual relativamente alto $(11,4 \%)$ de usuários afirmou que não conseguiu ser atendido na UBS sem consulta marcada. Se acrescermos os usuários que já não buscam a unidade por não terem a expectativa de serem atendidos, podemos considerar que $42,7 \%$ não são adequadamente acolhidos, revelando ainda haver necessidade de se qualificar a maneira como as equipes têm implantado o acolhimento em suas unidades. $\mathrm{O}$ tempo de espera também se apresenta como fator crítico para a qualidade do acolhimento, dado que longos tempos de espera podem motivar os usuários a buscarem alternativas ${ }^{22}$. Para esse item, embora os resultados tenham oscilado para baixo, os tempos médios de espera relatados pelos usuários se mantiveram abaixo de 30 minutos, 24,56 (2012) e 26,66 (2018), tempo considerado adequado para atendimento de urgência, mesmo para unidades de média e alta complexidade ${ }^{23}$.

Os dados que tratam da organização da agen$d a$ das equipes para facilitar o modo como os usuários acessam consultas e como estabelecem um contato e comunicação mais fluídos com os profissionais de saúde mostram que, por um lado, houve melhoria geral para o conjunto de variáveis selecionadas, mas por outro, ainda persiste grande número de equipes que atuam impondo barreiras organizacionais de acesso. Quase $10 \%$ dos usuários, ao buscarem atendimento na unidade nas situações em que não há necessidade de atendimento no mesmo dia, não conseguem agendar a consulta no mesmo momento e são obrigados a retorna em dias e/ou momentos específicos para realizarem a marcação. Esse tipo de obstáculo, em muitas situações, força os usuários a procurarem outros serviços ou pode agravar o quadro clínico, os submetendo a maior desconforto e sofrimento e exigindo posteriores atendimentos de urgência.

$\mathrm{O}$ reordenamento das rotinas das equipes, com a incorporação de maior flexibilidade em seus processos organizativos pode constituir importante elemento para a modificação da maneira na qual usuários acessam os serviços de $\mathrm{AB}$. Equipes que facilitam o contato para que usuários possam buscar e mostrar resultados de exames e renovarem receitas sem a necessidade de agendamento alargam as possibilidades de utilização e satisfação dos usuários, e nesse aspecto, os dados evidenciam o esforço dos trabalhadores para se ajustarem a boas práticas de acesso para situações recorrentemente de demandas. 
Contudo, na perspectiva dos usuários, os resultados não foram tão bons, apesar da constatação de melhoria no período analisado. Elevada proporção de usuários afirmaram que não conseguem agendar atendimentos em qualquer dia ou horário. Ainda resiste a lógica de dias e horários específicos para marcação de consultas em todos os contextos. Esse quadro foi constatado em diferentes estudos que revelaram a permanência de marcação em dias específicos, com filas formadas na madrugada para conseguir fichas que são distribuídas por ordem de chegada ${ }^{24,25}$. Com a popularização do acesso à internet e aparelhos portáteis, a introdução de mecanismos mais ágeis e facilitados para o agendamento e cancelamento de atendimentos, de maneira a encurtar os tempos entre a marcação e a consulta, com a gestão inteligente de listas de espera, torna-se tarefa essencial para a melhoria do acesso dos usuários aos serviços básicos de saúde, otimizando a oferta e diminuindo o absenteísmo.

Do mesmo modo, o atendimento em horários agendados facilita a organização da vida pessoal dos usuários, evitando o dispêndio de longos períodos de dedicação para acessar o atendimento, assim como extensos tempos de espera para a consulta, desde a chegada à unidade de saúde. Nesse aspecto, os dados revelam o predomínio de atendimentos agendados por turno e que são realizados por ordem de chegada. Apenas um quinto dos usuários informaram que sua equipe de referência atende com horário marcado, revelando o longo caminho que ainda se tem a percorrer para a qualificação dessa questão. Atendimentos com horário marcado exigem boa organização da unidade e, sobretudo, cumprimento da carga horária dos profissionais, questão ainda que apresenta problemas na realidade da $\mathrm{AB}$.

Finalmente, ao analisarmos os resultados para a subdimensão tempo de espera entre a busca pelo serviço e a efetivação do atendimento, constatamos melhoria para o período. Ao serem questionados sobre o tempo de espera para o agendamento de primeira consulta de usuários com hipertensão arterial sistêmica e diabetes mellitus, os profissionais respondentes indicaram que o número médio de dias de espera reduziu em 1,5 dias. Para hipertensos foi de 6,04 (2012) e 4,41 (2018) e para pessoas com diabetes foi de 5,93 (2012) e 4,21 (2018). Por se tratar de grupos historicamente prioritários para a $\mathrm{AB}$, os tempos de espera desses usuários funcionam como bom marcador para essa subdimensão. O encurtamento do tempo que usuários aguardam para acessar $o$ atendimento pode ressignificar a rela- ção que estabelece com o serviço, reposicionando a sua percepção sobre a qualidade do que lhe é ofertado e também diminuindo o absenteísmo ${ }^{26}$.

\section{Considerações finais}

O acesso à saúde e, em particular à atenção básica, é um direito elementar dos cidadãos e vem se fortalecendo desde o processo de redemocratização ocorrido no final dos anos 1980, com a ampliação gradual da oferta de serviços em todo o país.

Como vimos ao longo do presente estudo, a disponibilidadede serviços de $\mathrm{AB}$ apresentou importantes avanços, com a diminuição de vazios assistenciais, apesar de ainda haver significativos espaços que padeçam da ausência de oferta, sobretudo no Sudeste, que segue apresentando as mais baixas coberturas. Para os territórios que dispõem de UBS, quando se trata da estrutura física e arquitetônica, constatou-se melhoria das condições das unidades, sobretudo no Norte, e menores cidades, mas, ainda assim, persistem situações desfavoráveis para pessoas com dificuldades de mobilidade em boa parte delas.

Para a dimensão organizacional, a incorporação do acolhimento à demanda espontânea como dispositivo de melhoria do acesso se estendeu para a grande maioria das equipes analisadas, com elevações mais expressiva no Norte, Centro-Oeste e cidades de menor porte, apesar de os dados revelarem que a qualidade do acolhimento implantado ainda enfrenta consideráveis desafios. Equipes passaram a se dedicar mais claramente a organizar e garantir o acolhimento, mas parcela significativa delas não o desenvolvem de maneira adequada. Para os usuários, houve importante avanço no que se refere a existência e a qualidade do acolhimento, mas, ao mesmo tempo, permanecem importantes obstáculos e desafios para que sejam satisfatoriamente acolhidos.

Quanto à organização da agenda, os dados apontam para uma melhoria nas condições gerais de acesso, sem com isso deixarem de indicar dificuldades a serem enfrentadas, tais como a existência de usuários que não conseguem sair com consulta agendada em situações nas quais não há necessidade de atendimento no mesmo dia, os elevados percentuais de usuários que precisam agendar consultas para mostrar resultados de exames e renovarem receitas, e de equipes que mantém dias e horários específicos para realizar o agendamento de consultas e que não asseguram atendimento com horário marcado. 
Na dimensão temporal, verificou-se que quase a totalidade das unidades possuem dias e horários de funcionamento compatíveis com o recomendado, porém, usuários que vivem nas grandes cidades demonstraram maior descontentamento, indicando a importância de se processarem ajustes que assegurem horários mais adequados a essa realidade, como em turnos adicionais ou finais de semana. E quando se trata do tempo de espera entre o agendamento e o atendimento, os resultados também demonstraram melhoria no acesso, na medida em que se verificou diminuição no número médio de dias de espera para grupos populacionais prioritários.
Um melhor acesso é elemento central para maior adesão e engajamento dos cidadãos em defesa do SUS e desafio permanente para gestores e trabalhadores. O conjunto dos resultados aqui apresentados sinaliza para uma melhoria progressiva do acesso aos serviços básicos de saúde em todas as realidades do país, mas também informa sobre problemas recorrentes que ainda precisam ser enfrentados, se se pretende alcançar patamares compatíveis com a demanda e necessidade da sociedade brasileira.

\section{Colaboradores}

ANA Sousa respondeu pela concepção, delineamento, análise e interpretação dos dados, e redação final do artigo. HE Shimizu, pela concepção, delineamento e revisão do artigo. 


\section{Referências}

1. Hortale VA, Conill EM, Pedroza M. Desafios na construção de um modelo para análise comparada da organização de serviços de saúde. Cad Saude Publica 1999; 15(1):79-88.

2. Giovanella L, Escorel S, Lobato LVC, Noronha JC, Carvalho AI, organizadores. Políticas e sistemas de saúde no Brasil. 2a ed. Rio de Janeiro: Editora Fiocruz; 2012.

3. Paim JS, Travassos C, Almeida C, Bahia L, Macinko J. The Brazilian health system: history, advances, and challenges. The Lancet 2011; 377(9779):1778-1797.

4. Paim JS. Bases conceituais da reforma sanitária brasileira. In: Fleury S, organizadora. Saúde e democracia, a luta do CEBES. São Paulo: Lemos;1997.

5. Brasil. Ministério da Saúde (MS). Histórico de cobertura da atenção básica [acessado 2019 nov 14]. Disponível em: https://egestorab.saude.gov.br/paginas/acessoPublico/relatorios/relHistoricoCobertura.xhtml

6. Macinko J, Mendonça CS. Estratégia Saúde da Família, um forte modelo de atenção primária à saúde que traz resultados. Saude Debate 2018; 42(n. esp.):18-37.

7. Malta DC, Santos MAS, Stopa SR, Vieira JEB, Melo EA, Reis AAC. A cobertura da Estratégia de Saúde da Família (ESF) no Brasil, segundo a Pesquisa Nacional de Saúde, 2013. Cien Saude Colet 2016; 21(2):327-338.

8. Oliveira LS, Almeida LGN, Oliveira MAS, Gil GB, Cunha ABO, Medina MG, Pereira RAG. Acessibilidade a atenção básica em um distrito sanitário de Salvador. Cien Saude Colet 2012; 17(11):3047-3056.

9. Vasconcelos LR, Pagliuca MF. Mapeamento da acessibilidade do portador de limitação física a serviços básicos de saúde. Esc Anna Nery R Enferm 2006; 10(3):494-500.

10. Campos RTO, Ferrer AL, Gama CAP, Campos GWS, Trapé TL, Dantas DV. Avaliação da qualidade do acesso na atenção primária de uma grande cidade brasileira na perspectiva dos usuários. Saude Debate 2014; 38(n. esp.):252-264.

11. Souza ECF, Vilar RLA, Rocha NSPD, Uchoa AC, Rocha PM. Acesso e acolhimento na atenção básica: uma análise da percepção dos usuários e profissionais de saúde. Cad Saude Publica 2008; 24(Supl. 1):S100-S110.

12. Penchansky DBA, Thomas JW. The concept of access: definition and relationship to consumer satisfaction. Med Care 1981; 19(2):127-140.

13. Unglert CVS. O enfoque da acessibilidade no planejamento da localização e dimensão de serviços de saúde. Rev Saude Publica 1990; 24(6):445-452.

14. Travassos C, Martins M. Uma revisão sobre os conceitos de acesso e utilização de serviços de saúde. Cad Saude Publica 2004; 20(Supl. 2):S190-S198.

15. Giovanella L, Fleury S. Universalidade da atenção à saúde: acesso como categoria de análise. In: Eibenschutz C, organizadora. Política de saúde: o público e o privado. Rio de Janeiro: Editora Fiocruz; 1996. p. 177-198.
16. Donabedian A. Aspects of medical care administration. Boston: Harvard University Press; 1973.

17. Andersen RM. Revisiting the behavioral model and access to medical care: does it matter? Health Soc Behav 1995; 36(1):1-10.

18. Garnelo L, Lima JG, Rocha ESC Herkrath FJ. Acesso e cobertura da Atenção Primária à Saúde para populações rurais e urbanas na região norte do Brasil. Saude debate 2018; 42(n. esp.):81-99.

19. Facchini LA, Tomasi E, Dilélio AS. Qualidade da Atenção Primária à Saúde no Brasil: avanços, desafios e perspectivas. Saude debate 2018; 42(n. esp.):208-223.

20. Moura BLA, Cunha RC, Fonseca ACF, Aquino R, Medina MG, Vilasbôas ALQ, Xavier AL, Costa AF. Atenção primária à saúde: estrutura das unidades como componente da atenção à saúde. Rev Bras Saude Matern Infant 2010; 10(Supl. 1):S69-S81.

21. Merhy EE, Campos GWS, Cecílio LCO, organizadores. Inventando a mudança na saúde. São Paulo: Editora Hucitec; 1994.

22. Ansell D, Crispo JAG, Simard B, Bjerre LM. Inteventions to reduce wait times for primary care appointments: a systematic review. BMC Health Services Research 2017; 17(295):1-9.

23. Gusmão FAR. Análise de implantação da Política de Qualificação da Atenção à Saúde do Sistema Único de Saúde - Política Qualisus - em três hospitais do município do Recife. [tese]. Recife: Centro de Pesquisas Aggeu Magalhães, Fundação Oswaldo Cruz; 2008.

24. Assis MMA, Villa TCS, Nascimento MAA. Acesso aos serviços de saúde: uma possibilidade a ser construída na prática. Cien Saude Colet 2003; 8(3):815-823.

25. Mendes ACG, Miranda GMD, Figueiredo KEG, Duarte PO, Furtado BMASM. Acessibilidade aos serviços básicos de saúde: um caminho ainda a percorrer. Cien Saude Colet 2012; 17(11):2903-2912.

26. Silveira GS, Ferreira PR, Silveira DS, Siqueira FCV. Prevalência de absenteísmo em consultas médicas em unidade básica de saúde do sul do Brasil. Rev Bras Med Fam Comunidade 2018; 13(40):1-7.

Artigo apresentado em 28/03/2020

Aprovado em 29/04/2020

Versão final apresentada em 01/05/2020

Editores-chefes: Romeu Gomes, Antônio Augusto Moura da Silva 
